\title{
VLF SURFACE-IMPEDANCE MEASUREMENTS FOR ICE-DEPTH MAPPING IN THE ANTARCTIC
}

\author{
By David V. Thiel and Fiona Neall
}

(Division of Science and Technology, Griffith University, Nathan, Queensland 4111, Australia)

ABSTRACT. VLF surface-impedance measurements were made along four traverses on the Antarctic ice sheet in the vicinity of Casey base. Computer modelling of the surface-impedance data allowed ice-depth predictions to be made; predictions which are almost independent of ice temperature for ice depths less than $800 \mathrm{~m}$. Results agree with ice-radar and other ice-depth data. Surface-impedance anomalies were observed close to moraines and crevasses in the ice sheet. The technique is fast and the instrumentation sufficiently portable for single-person operation.

\section{INTRODUCTION}

The possiblity of using VLF surface-impedance measurements as an ice-depth probe was first suggested and tested over a temperate glacier in South Island, New Zealand, by Thiel (1986). Descriptions of the theory, equipment, method of operation, and data analysis were included in that paper. No independent depth measurements were available on that occasion and so no direct check on the method was available. This paper reports an attempt to verify the procedure on known ice environments in the general area of Casey base, Antarctica, during the summer of 1987-88. A surface-impedance meter capable of operating in a sub-zero temperature environment was constructed following the general principles outlined previously (Thiel, 1986). Casey base was used because of the considerable effort that has been made in mapping the adjacent Law Dome by Australian National Antarctic Research Expeditions (ANARE) glaciologists over the last 30 years (Betts, 1981). As with previous instruments, the surface-impedance meter used transmissions from North West Cape (NWC, W.A.) as a radiation source.

Figure 1 illustrates the variation of surface impedance (measured at $22.3 \mathrm{kHz}$ ) with ice depth for a number of different ice-electrical parameters (i.e. conductivity and dielectric constant). These characteristics have been found to vary with temperature (Reynolds, 1985). Note that for depths of less than approximately $800 \mathrm{~m}$ (as was the case in this investigation), the surface impedance is essentially independent of ice temperature.

\section{VLF SIGNAL CHARACTERISTICS}

It has been known for some time that VLF signals are severely attenuated for propagation across polar ice caps (Westerlund and Reder, 1973). As Casey base and NWC lie almost on the same longitude, ice-cap absorption of the signal was negligible. The signal strength at Casey base was approximately the same as that found at Brewster Glacier, New Zealand (Thiel, 1986). The great-circle path lengths are 5.6 and $6.2 \mathrm{Mm}$, respectively, so this is not unexpected.

Short-term fluctuations did require the operator to average 12 readings at each location. This resulted in an error in the surface impedance of approximately $4 \%$. The phase-detector circuit failed to operate throughout field operations. Interpretation of data was therefore only possible

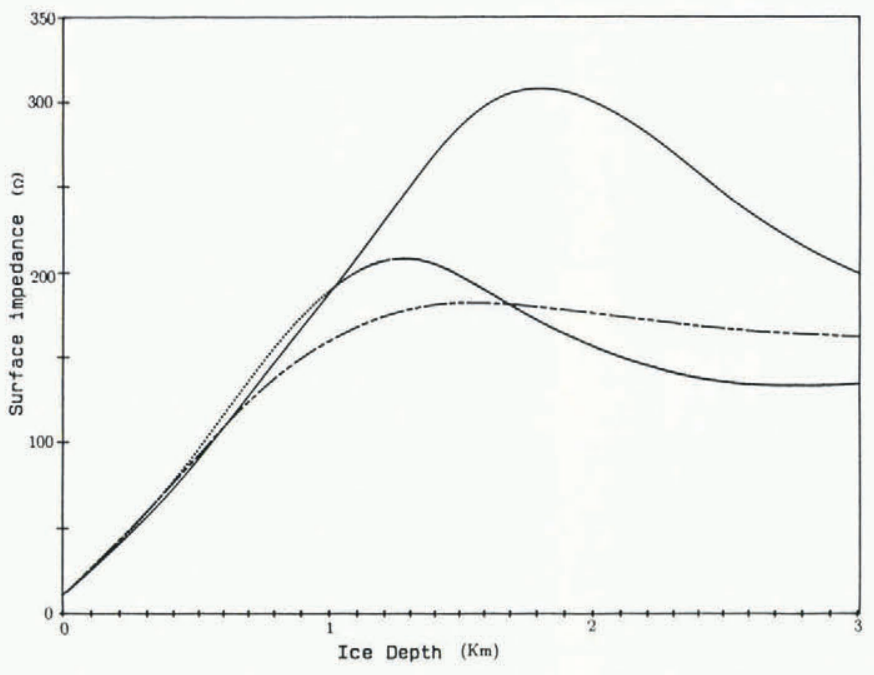

Fig. 1. Theoretical plot of surface impedance as a function of ice depth above a rock sub-surface with a conductivity of $1.5 \times 10^{-3} \mathrm{~S} \mathrm{~m}^{-1}$ and dielectric constant of $15 \varepsilon_{0}$. Three different sets of ice parameters have been used: continuous line, conductivity $3 \times 10^{-6} \mathrm{~S} \mathrm{~m}^{-1}, 3 \varepsilon_{0} ;$ dotted line, conductivity $6.6 \times 10^{-6} \mathrm{~S} \mathrm{~m}^{-1}, 4.5 \varepsilon_{0} ;$ broken line, conductivity $6.6 \times 10^{-6} \mathrm{~S} \mathrm{~m}^{-1}, 1 \varepsilon_{0}$.

using a two-layer method. This precluded the possibility of mapping gravel at the base of the ice (Thiel, 1986).

It is important to note that the signal response is maximized when the electric field antenna (a $10 \mathrm{~m}$ insulated wire lying on the surface) is oriented in the direction of the transmitter. Thus, readings were always taken with a north-south orientation. When the traverse direction was west-east, the instrument was re-oriented at each point.

\section{TRAVERSE RESULTS}

This paper reports four surface-impedance traverses labelled T1 to T4 conducted close to Casey base, Antarctica, during February-March 1988. The T1 (4 km long) and T2 ( $1 \mathrm{~km}$ long) traverses are shown in Figure 2. Computer modelling was used to convert the surface-impedance data to ice depth and the complex dielectric constants of ice and bedrock. T4, the shortest traverse of $120 \mathrm{~m}$, crossed an isolated crevasse in an attempt to clarify the behaviour of the surface-impedance parameter in the vicinity of crevasses observed previously (Thiel, 1986). The other three traverses, $\mathrm{T} 1, \mathrm{~T} 2$, and $\mathrm{T} 3$, were undertaken for ice-depth mapping.

The rock/bedrock referred to throughout this paper is predominantly high-grade gneiss with varying concentrations of feldspar, quartz, biotite, and garnet. The concentration of biotite in particular is thought to influence the surfaceimpedance measurements made on rock platforms. 


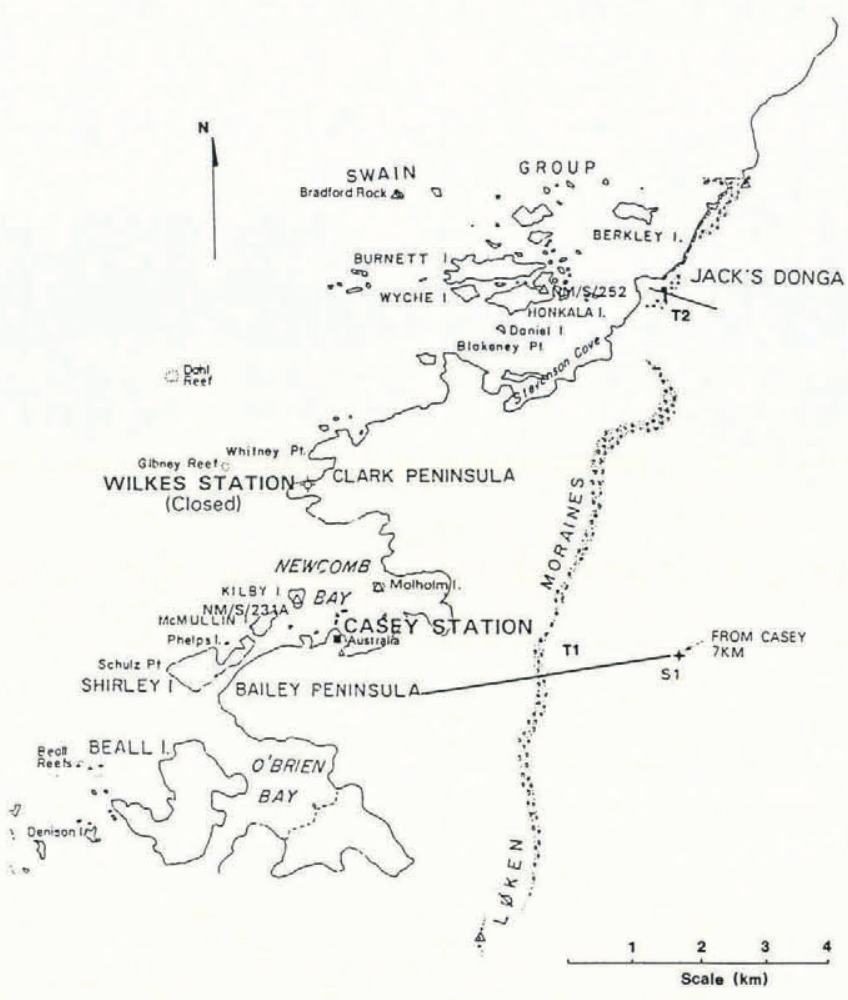

\section{Casey Area}

Fig. 2. Map of Casey base environs showing the surface-impedance traverse locations T1-T2.

\section{TI: Penguin Pass to S1}

The route started from exposed rock to the east of Casey base and continued for $4 \mathrm{~km}$ to a survey point designated S1. This line crosses the Løken moraines at a point where they are not clearly exposed at the surface but are evident on the ice-radar profile from 1.4 to $2.4 \mathrm{~km}$. Readings were made every $250 \mathrm{~m}$ using a vehicle odometer to determine the distance. Ice conditions during the traverse included almost no snow, somewhat weathered ice to the west of the moraine, and blue ice to the east of the moraine.

The ice-radar result is plotted in Figure 3 along with the ice depth derived from surface-impedance measurements. The depth at S1 is approximately $200 \mathrm{~m}$. The surfaceimpedance data were converted to ice depth using a simple two-layer model, i.e. ice on bedrock. The following parameters were used: ice conductivity $=6.6 \times 10^{-6} \mathrm{~S} \mathrm{~m}^{-1}$; ice dielectric constant $=4.5 \varepsilon_{0} ;$ rock conductivity $=$

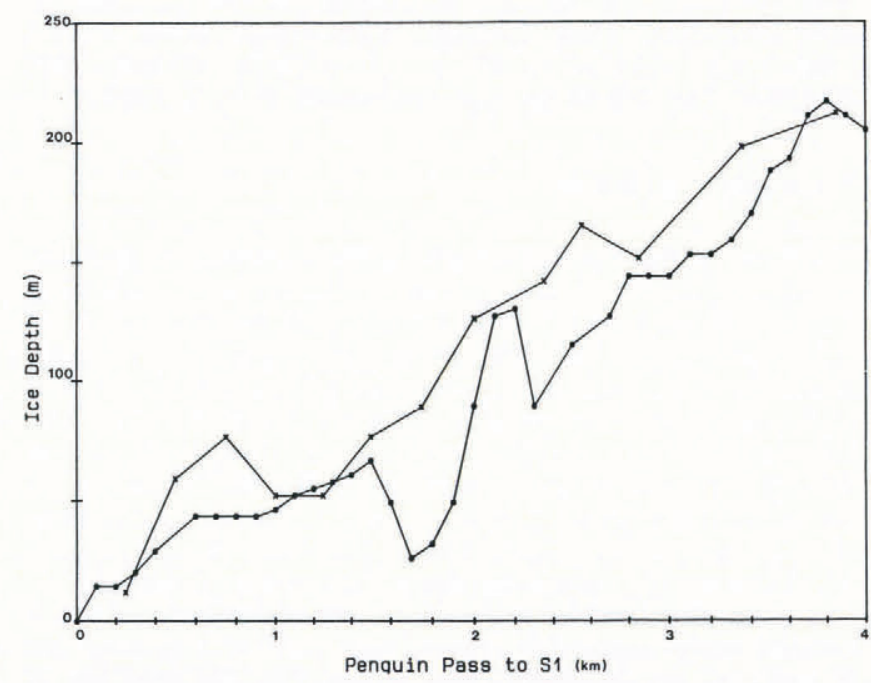

Fig. 3. TI ice-depth profile comparison between ice radar (dots) and surface impedance (crosses).
$1.5 \times 10^{-3} \mathrm{~S} \mathrm{~m}^{-1}$; rock dielectric constant $=15 \varepsilon_{0}$, where $\varepsilon_{0}$ is the permittivity of free space. The ice parameters, chosen from the $-27^{\circ} \mathrm{C}, 20 \mathrm{kHz}$ data given by Reynolds (1985), were thought to be most appropriate to ice conditions at all measurement sites. Uncertainties in ice temperature, bedrock characteristics, and noise in the measurements are estimated to result in a depth-estimate uncertainty of $10 \%$.

From Figure 3 one can conclude that surfaceimpedance measurements have penetrated the moraine, whereas the ice radar has mapped the top of the moraine The rock band is clearly quite steeply dipping, rising from a depth of $120 \mathrm{~m}$ to $30 \mathrm{~m}$ over a horizontal distance of $600 \mathrm{~m}$. This distinction between ice-radar and surfaceimpedance measurements is a potentially useful tool in glaciology.

\section{T2: "Jack's Donga"}

Two traverses were made from the outcropped rock close to the sea, across the triple banded moraine towards the Law Dome peak. (The name "Jack's Donga" refers to a hut located in the area.) An approximate altitude profile of the area is given in Figure $4 \mathrm{a}$ along with two series of ice-depth estimations from surface-impedance data (Fig. 4b). A photograph of the protruding moraines is given in Figure 5 .

As with $\mathrm{T} 1$, the instrument was oriented north-south and consequently was almost parallel to the relatively narrow moraine bands. The surface expression of these moraines was approximately $20-30 \mathrm{~m}$ wide in all three cases. While there is a dramatic effect at the ice/moraine boundary at the surface, the $\mathrm{T} 1$ result suggests that sub-surface mapping of the moraine is not possible using surface-impedance measurements. It is concluded that this plot gives information predominantly about the depth to bedrock under the ice. Rock sizes in the moraines varied up to a maximum of approximately $1 \mathrm{~m}$ in height. The complete traverse was pegged at each measurement station and so repeat readings were made in almost exactly the same locations.

The general trend in both traverses is an increase in ice depth to the east. Two of the narrow moraines are clearly evident on Figure $4 \mathrm{~b}$ as anomalously high ice-depth estimates. It is of interest to note that the slope of the ice immediately in front of the moraines coincides with a rapid increase in elevation of the ice surface. Similarly, the relatively constant ice depth to the east of the moraines coincides with an almost horizontal ice "pool". All visible
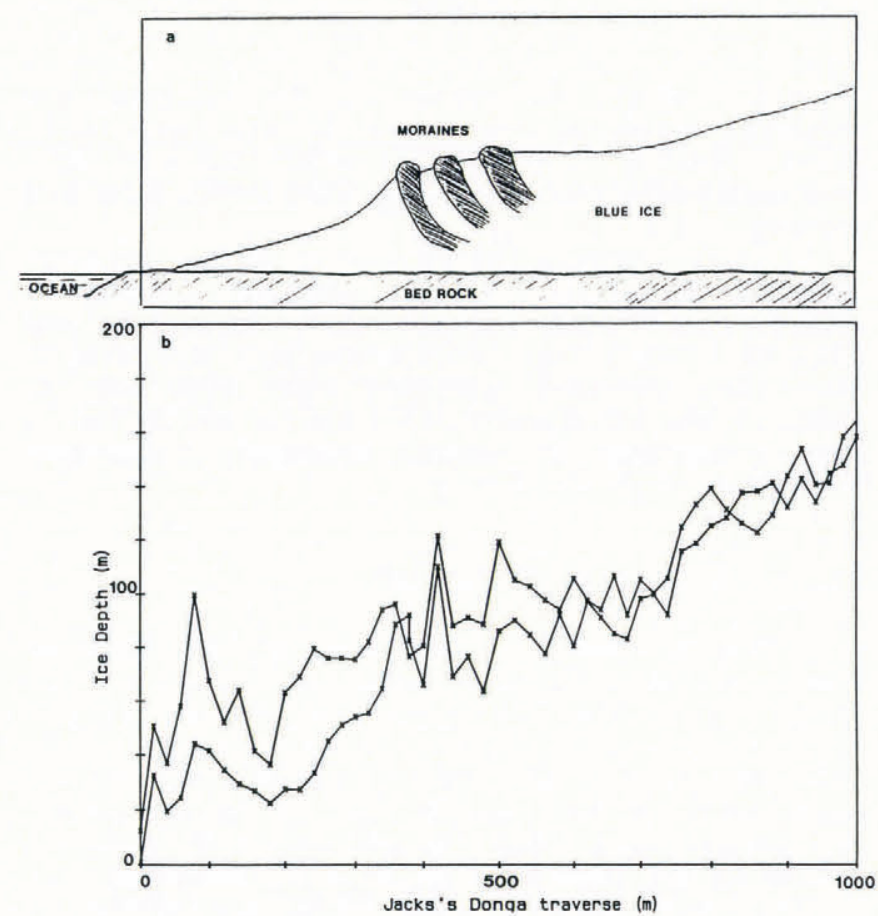

Fig. 4. Traverse T2 earth-plane cross-section (showing approximate altitude changes) (a), and ice depth deduced from surface-impedance measurements (b). 


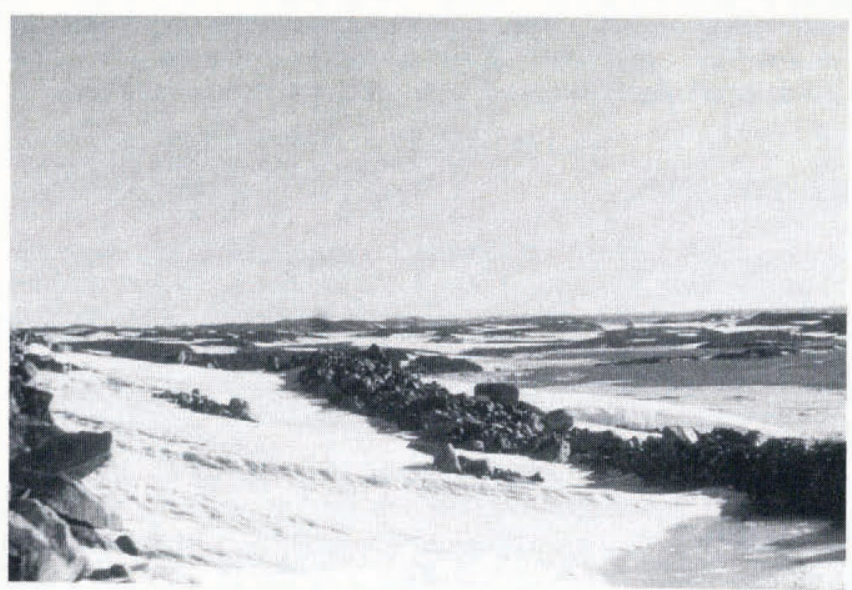

Fig. 5. Photograph of the Loken moraines crossed by T2. The view is to the south with the ocean on the right. The surface expression of the moraines is approximately $1-2 \mathrm{~m}$ high.

rock features, including the exposed rock on the shore and adjacent islands, indicate a very flat rock topography. This is assumed to be the case under the ice cap as well. The parameters used in this model are identical to those used for the T1 analysis with a similar uncertainty estimate.

The very large ice-depth estimate at $100 \mathrm{~m}$ coincided with a large pool of water in the ice. Other rapid variations in the first $200 \mathrm{~m}$ are thought to result from ice/rock contacts near the surface. These effects are even more dramatic in $\mathrm{T} 3$.

The only independent depth measurement (Division of National Mapping, 1970) suggests a depth of $160 \mathrm{~m}$ at the end of the traverse which lies well within the uncertainty range.

It is assumed that the change in melt conditions on the weathered ice surface to the east of the moraines is the reason for the somewhat different ice-depth determinations between the two traverses.

\section{T3: Penguin Pass}

A short traverse was made across an ice-filled basin in the vicinity of Penguin Pass. In this case, the ice was thought to be relatively shallow and was visibly weathered with air and water dispersed in the shallow sub-surface. The two traverses are shown in Figure 6. It is clear in this traverse that the surface impedance over ice is lower than that of the surrounding rock as the traverse started and ended on rock. The general features of the plot include a broad minimum and two maxima close to the edge of the ice bowl. The spot surface-impedance values on the rocks differ from one side to the other. Without the phase

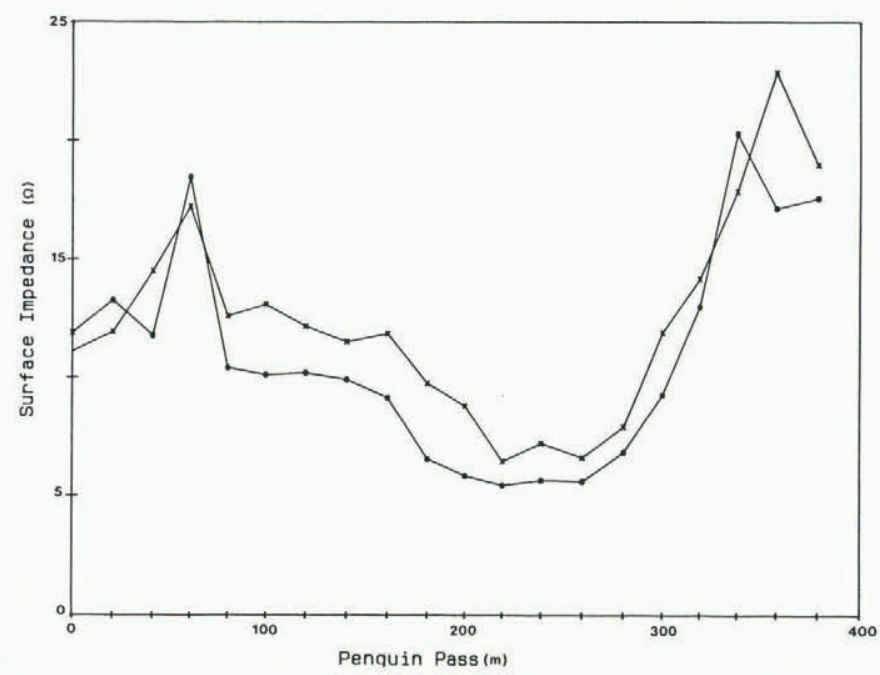

Fig. 6. Surface-impedance measurements crossing weathered ice between two rock outcrops (T3 traverse). information, this profile is impossible to model. It is clear, however, that the surface impedance at the likely maximum ice depth is a minimum. This is contrary to the previous data modelled using two layers only. One can only conclude that either the ice itself is more conductive due to the presence of water or that the bottom of the basin is filled with water-saturated moraine or gravel. The surfaceimpedance maxima on both sides of the traverse are thought to result from the rock/air/ice gap caused by the more rapidly changing thermal conditions of the ice close to rock. These peaks are similar to the effect noted at the moraines in traverse $\mathrm{T} 2$.

\section{T4: Crevasse}

A $120 \mathrm{~m}$ traverse was made across a crevasse oriented almost parallel to the transmitter bearing angle. This is virtually identical to the situation reported previously (Thiel, 1986) where the crevasse lies approximately $20^{\circ}$ to the traverse path. The crevasse was almost vertical in orientation and was covered by a $2 \mathrm{~m}$ thick snow bridge. Its width at the surface was $3 \mathrm{~m}$, it was at least $30 \mathrm{~m}$ deep, and was roughly $400 \mathrm{~m}$ long. It appeared to be at least $500 \mathrm{~m}$ from other crevasses in the area and so ideal for an investigation into the effect of crevasses on surface-impedance measurements.

The surface-impedance profile over the slot is shown in Figure 7. Clearly evident at $70 \mathrm{~m}$ is a surface-impedance

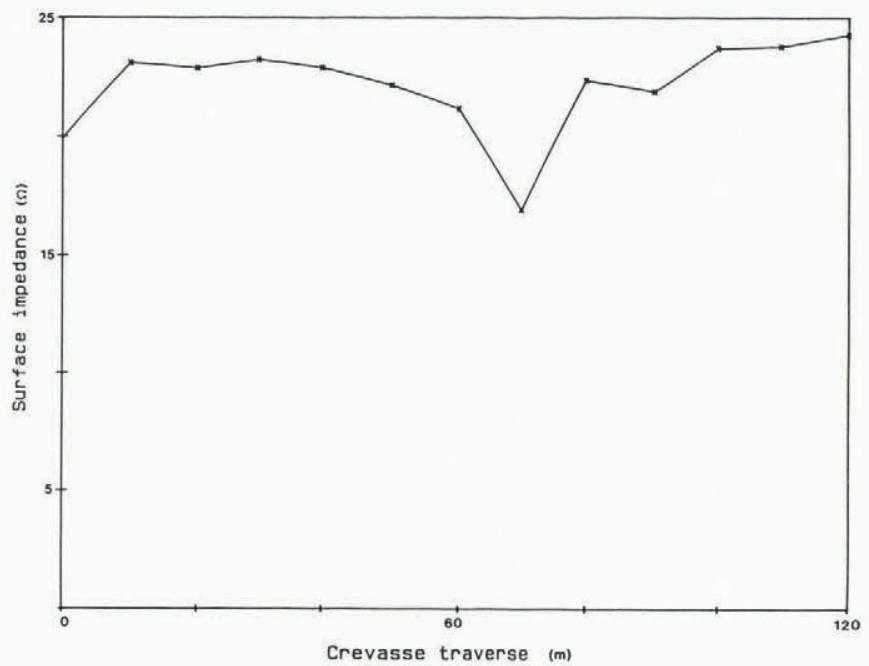

Fig. 7. T4 surface-impedance measurements across a crevasse in blue ice.

minimum which coincides with the instrument located on the snow bridge covering the crevasse. This indicates that abrupt variations do occur in the vicinity of crevassing. It is worthy of note that, at the $0 \mathrm{~m}$ position, the surface impedance is somewhat lower than at the adjacent points, suggesting the presence of another crevasse. None was evident on the surface but an ice cleavage that did not reach the surface may explain the effect. It was unusual that this crevasse was quite isolated.

\section{COMMENTS AND CONCLUSIONS}

It has been demonstrated that for blue-ice areas a measure of the VLF surface impedance allows ice depths to be determined. While the nature of the surface (i.e. the presence of melt water) does influence the readings and so the resultant ice-depth interpretation, it is thought that this effect can be removed by insulating the instrument chassis from the ice surface, a minor instrument modification. The presence of moraines and crevasses does influence the profiles obtained by showing quite large rapid surface-impedance changes. The computer modelling of traverses $\mathrm{T} 1$ and $\mathrm{T} 2$ yielded consistent electrical properties of ice and rock which could be used as a guide for future surface-impedance mapping. These numerical values are in keeping with previous ice-depth measurements (Thiel, 1986) and Antarctic ice measurements (Glen and Paren, 1975). 
While the complex dielectric properties of ice vary with temperature, frequency, and formation parameters (Reynolds, 1985), at the frequency of measurement the depth uncertainties resulting from these unknowns is estimated to result in an error of approximately $10 \%$ in the absolute depth. In regions where the ice depth exceeds $800 \mathrm{~m}$, the ice temperature will be important in ice-depth estimations from surface-impedance measurements.

There is good evidence to support the idea that, whereas ice-radar measurements will give information about the first ice/rock interface, surface-impedance measurements have the potential to map beneath narrow moraines and to yield information about gravel layers at bedrock.

\section{ACKNOWLEDGEMENTS}

The authors gratefully acknowledge the assistance of Australian National Antarctic Research Expeditions (ANARE) within the Antarctic Division of the Department of Science in making this research possible, the Glaciology Section of the Department of Meteorology at the University of Melbourne for making available the ice-radar data, and also two grants from Griffith University Research Committee for equipment and salary expenses associated with the project. The authors also wish to thank an anonymous reviewer for drawing attention to the temperature dependance of electrical characteristics of ice.

\section{REFERENCES}

Betts, M.S. 1981. Australian publications in Antarctic atmospheric sciences, 1947-80. Canberra, Department of Science and Technology. Antarctic Division. (Information Folder 19.)

Division of National Mapping. 1970. Australian Antarctic Territory map No. SQ49-50. Canberra, Department of National Development.

Glen, J.W. and J.G. Paren. 1975. The electrical properties of snow and ice. J. Glaciol., 15(73), 15-38.

Reynolds, J.M. 1985. Dielectric behaviour of firn and ice from the Antarctic Peninsula, Antarctica. J. Glaciol., 31(109), 253-262.

Thiel, D.V. 1986. A preliminary assessment of glacial ice profiling using VLF surface-impedance measurements. $J$. Glaciol., 32(112), 376-382.

Westerlund, S. and F.H. Reder. 1973. VLF radio signals propagating over the Greenland ice-sheet. J. Atmos. Terr. Phys., 35(8), 1475-1491.

MS. received 6 December 1988 and in revised form 25 April 1989 